Eka Ratnawati

Kebutuhan Remaja Mempersiapkan Perawatan Kebersihan Menstruasi Di Daerah Pedesaan

\title{
Kebutuhan Remaja Mempersiapkan Perawatan Kebersihan Menstruasi Di Daerah Pedesaan
}

\section{Eka Ratnawati}

Akademi Keperawatan Ngesti Waluyo

Korespondensi penulis: ekaratnawati34@gmail.com

\begin{abstract}
Abstrak
Remaja mengalami perubahan pesat, baik secara biologis, psikologis maupun sosial dalam masa pubertas menuju ke tahap perkembangan dewasa. Perubahan yang paling mencolok dalam masa ini adalah terjadinya menarche. Remaja harus dipersiapkan untuk menghadapi menarche agar mampu melakukan perawatan menstruasi dengan benar. Remaja di daerah pedesaan banyak mengalami keterbatasan, terutama akses informasi yang benar tentang menstruasi dan perawatannya. Tujuan dari penelitian ini yaitu untuk mengetahui kebutuhan remaja untuk mampu melakukan perawatan kebersihan menstruasi di daerah pedesaan. Teknik pengambilan sampel menggunakan Purposive sampling yang melibatkan 7 orang remaja putri usia 10-14 tahun di Desa Simpar, Tretep, Temanggung. Penelitian dilakukan pada bulan Juni 2016 sampai dengan Januari 2017, melalui FGD. Analisis data dilakukan secara manual dengan content analysis. Muncul 6 tema dalam penelitian ini, yakni: 1) Remaja memerlukan informasi yang lengkap dan benar tentang menstruasi dan perawatan menstruasi, 2) Remaja memerlukan sumber informasi yang bisa diakses dengan mudah dan privasi, 3) Perlu pemilihan waktu yang tepat dalam penyampaian informasi, 4) Remaja perlu bantuan awal saat mengalami menarche, 5) Tindakan responsif yang harus dilakukan saat terjadi menarche, 6) Remaja memerlukan fasilitas perawatan kebersihan menstruasi yang layak. Remaja di daerah pedesaan sangat memerlukan informasi dan penjelasan dengan lengkap dan benar dari orang terdekat (ibu) dan orang yang berpengaruh (guru) tentang perawatan kebersihan menstruasi dan tindakan yang harus segera dilakukan saat terjadi menarche. Proses penyampaian informasi ini harus dilakukan sebelum remaja mengalami menarche.
\end{abstract}

Kata kunci: remaja; menarche; menstruasi; perawatan menstruasi

\section{PENDAHULUAN}

Prediksi jumlah remaja putri tahun 2000-2025 menurut Badan Pusat Statistik (BPS) akan mengalami peningkatan 10,1 juta jiwa. Jumlah yang besar ini harus mendapatkan perhatian khusus, terkait kesehatan reproduksinya. Remaja yang tinggal di daerah pedesaan rentan mengalami berbagai keterbatasan akses untuk informasi tentang kesehatan reproduksi, termasuk menstruasi dan pengelolaannya (Badan Pusat Statistik, Nasional, Kesehatan, \& DHS, 2013).

Remaja merupakan masa transisi dari anak menjadi dewasa, dengan beberapa perubahan fisik, psikologis dan sosial. Menarche merupakan penanda utama terjadinya pubertas remaja (Kusmiran, 2013). Remaja sangat rentan mengalami gangguan kesehatan reproduksi jika tidak melakukan perawatan kebersihan selama menstruasi dengan benar. Di satu sisi, remaja mengalami kurang 
Eka Ratnawati

Kebutuhan Remaja Mempersiapkan Perawatan Kebersihan Menstruasi Di Daerah Pedesaan

pengetahuan tentang hal ini, namun faktor budaya dan pengaruh masyarakat yang menganggap tabu untuk memperbincangkan hal ini menjadi hambatan tersendiri (Kumalasari \& Andhyantoro, 2013).

Remaja yang tinggal di daerah pedesaan mendapatkan paparan informasi yang kurang tentang perawatan menstruasi ini. Ibu, yang merupakan sumber informasi utama tentang menstruasi enggan memperbincangkannya dengan remaja, karena merasa tidak cukup memiliki pengetahuan yang benar, dan terlebih rasa malu atau tabu terhadap topik ini. Ibu merasa bahwa menstruasi adalah wajar dan alami terjadi pada semua wanita, maka sampai pada waktunya tiba nanti, remaja dengan sendirinya akan paham tentang tindakan yang harus dilakukan saat mengalami menarche (Ratnawati, Prabandari, \& Nisman, 2018). Tujuan penelitian ini adalah untuk mengetahui kebutuhan remaja dalam mempersiapkan perawatan kebersihan menstruasi di daerah pedesaan.

\section{METODE}

Penelitian ini merupakan penelitian kualitatif fenomenologi. Metode ini digunakan untuk mendapatkan data yang mendalam dari partisipan. Tehnik memperoleh data dalam penelitian ini adalah FGD, observasi dan triangulasi (Sugiyono, 2015). Untuk menyampaikan hasil penelitian dengan jelas, maka dalam pelaporan ini menggunakan Consolidated Criteria for Reporting
Qualitative Research (COREQ) (Tong, Sainsbury, \& Craig, 2007).

Partisipan yang dilibatkan harus memenuhi kriteria inklusi, yakni remaja putri dengan usia 10-14 tahun yang tinggal di Desa Simpar, Kecamatan Tretep, Kabupaten Temanggung. Kriteria lainnya adalah bersedia untuk meluangkan waktu melaksanakan FGD dan kesediaan untuk peneliti melakukan observasi terhadap fasilitas sanitasi rumah. Menilik remaja merupakan kelompok rentan, maka ijin dari orangtua diperlukan sebagai syarat untuk bisa menjadi partisipan.

Partisipan dalam penelitian ini adalah 7 orang remaja putri. Triangulasi dilakukan dengan wawancara terhadap ibu partisipan. Peneliti melibatkan key informant dalam melakukan rekrutasi partisipan, yakni istri perangkat desa (carik) setempat.

Pengumpulan data dilaksanakan dari bulan Juni 2016 sampai dengan Januari 2017. Data dikumpulkan dengan FGD, menggunakan panduan pertanyaan FGD yang merupakan pertanyaan semi-terstruktur pada remaja. Data FGD remaja yang dikumpulkan merujuk pada kebutuhan remaja dalam persiapan melakukan perawatan kebersihan menstruasi. Peneliti memimpin FGD secara langsung, dibantu oleh asisten peneliti dalam pencatatan dan perekaman suara dan video. Proses komunikasi selama FGD menggunakan Bahasa Indonesia bercampur dengan Bahasa Jawa, agar tidak terlalu tegang. 
Eka Ratnawati

Kebutuhan Remaja Mempersiapkan Perawatan Kebersihan Menstruasi Di Daerah Pedesaan

Panduan FGD dikembangkan
melalui literature review yang didiskusikan dengan pakar psikologi dan keperawatan maternitas. Pertanyaan FGD sejumlah 6 pertanyaan besar, meliputi: 1) pengetahuan awal remaja tentang menstruasi, 2) sumber informasi tentang menstruasi, 3) pengalaman menarche dan perawatan kebersihan menstruasi, 4) harapan tentang peristiwa menarche, 5) komunikasi dengan orangtua tentang menstruasi, 6) fasilitas perawatan kebersihan menstruasi yang tersedia di rumah dan di sekolah. Pada beberapa bagian FGD, peneliti melakukan probing untuk menggali lebih dalam data yang diberikan partisipan.

FGD berlangsung kurang lebih 90 menit, direkam menggunakan digital voice recorder, dan catatan lapangan dibuat selama FGD, observasi, dan wawancara dengan orangtua. Data fasilitas sanitasi rumah tangga dan sekolah dilakukan menggunakan check list observasi yang dikembangkan sendiri oleh peneliti berdasarkan literature review. Triangulasi sumber data dilakukan pada ibu partisipan, menggunakan tehnik wawancara mendalam selama kurang lebih 90 menit pada 7 orang ibu.

Analisis data dilakukan secara manual, dengan melakukan transkrip hasil wawancara dalam Bahasa Indonesia. Analisis data menggunakan content analysis, berdasarkan pernyataan partisipan yang disarikan dalam kata kunci, meaning unit, kategori sampai akhirnya memunculkan tema. Data disajikan dalam bentuk tabel, narasi dan pembahasan.

Penelitian ini telah mendapatkan persetujuan etik dari Medical and Health Research Ethics Committee (MHREC) Faculty of Medicine Gadjah Mada University-DR. Sardjito General Hospital. Sebelum melakukan FGD dan wawancara mendalam, tujuan dan ruang lingkup penelitian dijelaskan kepada partisipan. Penjelasan tentang hak dan tanggung jawab dijelaskan dalam informed consent yang diperoleh dari semua partisipan, dan ijin dari orangtua partisipan wajib didapatkan.

\section{HASIL}

Tujuh orang remaja dilibatkan dalam penelitian ini. Karakteristik partisipan tersebut dipaparkan dalam tabel 1 di bawah ini.

Tabel 1. Karakteristik partisipan $(n=7)$

\begin{tabular}{cc}
\hline Karakteristik & $\mathrm{n}(\%)$ \\
\hline Usia (tahun) & \\
10 & $1(14)$ \\
11 & $4(58)$ \\
12 & $1(14)$ \\
13 & $1(14)$ \\
14 &
\end{tabular}

Tingkat pendidikan yang sedang berlangsung SD

SMP

Status menarche

Sudah

Belum 
Eka Ratnawati

Kebutuhan Remaja Mempersiapkan Perawatan Kebersihan Menstruasi Di Daerah Pedesaan

\section{Remaja memerlukan informasi yang lengkap dan benar tentang menstruasi dan perawatan menstruasi}

Remaja mengungkapkan pemahamannya tentang menstruasi dan perawatan menstruasi, namun masih sangat sederhana. Pemahaman remaja ini masih sangat superfisial tentang menstruasi, yakni sebatas adanya darah kotor yang keluar dari alat kelamin dan terjadinya proses menjadi dewasa. Menurut remaja, menstruasi menandakan bahwa alat reproduksi wanita sudah mulai berfungsi. Hal ini diperkuat dengan pernyataan sebagai berikut:

“... berfungsinya alat reproduksi wanita (P1)"

"keluarnya darah kotor dari jenis kelamin (P3)"

"menanjak dewasa.. nggak tahu.. Cuma baca buku.. Kalau orang wanita itu mengalami menstruasi.. Menanjak dewasa gitu.. (P6)"

Remaja belum paham tentang siklus menstruasi, terutama pada fase awal setelah menarche. Remaja mengalami panik dan takut saat tidak mendapatkan menstruasi lagi pada bulan-bulan pertama setelah menarche. Remaja ini mengatakan takut kalau dirinya hamil dan takut kalau tidak mengalami menstruasi lagi selamanya. Saat muncul masalah ini, ada rasa sungkan dan malu, sehingga teman yang menjadi tempat untuk mengungkapkan keluhan ini, sampai akhirnya pada ibunya, karena dorongan saudara yang lain agar dibawa ke dokter untuk diperiksa. Respons ibu saat anak remajanya mengeluh tidak menstruasi hanya diam saja. Hasil ini diperkuat dengan pernyataan berikut:

"takut selamanya tidak $M$. Pertama M 1 minggu, terus 5 bulan nggak.. cerita sama bibi.. coba periksa saja gitu ... sudah mau bilang ibu tapi sudah $M$... cuma tanya kok tidak $M$ gitu ... belum ... ibu cuma diem (P5)"

"... panik ... takut hamil ... hehehe ... curhatnya sama teman (P6)”

Remaja masih belum paham tentang perawatan kebersihan menstruasi, terutama tentang frekuensi penggantian pembalut, cara membersihkan daerah genital dan cara mengelola pembalut yang kotor. Beberapa partisipan menyampaikan bahwa mengganti pembalut yang digunakan saat menstruasi menunggu sampai penuh, baru kemudian diganti dengan yang bersih. Volume darah yang keluar tergantung dari hari ke berapa menstruasi. Remaja membawa pembalut bersih dari rumah untuk ganti, walau tahu kalau di sekolah juga disediakan pembalut ini. Ibu tidak pernah menjelaskan cara membersihkan daerah kewanitaan, sehingga menurut persepsi remaja, cara membersihkan daerah kewanitaan adalah dengan menggunakan sabun agar wangi, karena darah menstruasi ini berbau amis. Tiga orang partisipan menyampaikan bahwa membersihkan daerah kewanitaan menggunakan handuk, dan 4 orang partisipan menyampaikan tidak disabun dan tidak dikeringkan. Selama di sekolah, ada 1 partisipan yang menyampaikan kondisinya yang tengah menstruasi pada guru olahraga agar tidak 
Eka Ratnawati

Kebutuhan Remaja Mempersiapkan Perawatan Kebersihan Menstruasi Di Daerah Pedesaan

diberikan perintah yang berat. Hal ini diperkuat dengan pernyataan berikut:

"mengganti kalau sudah penuh ... bawa pembalut dari rumah, di TU juga ada ... kan tergantung harinya .. kalau hari ke-2 kadang banyak ... hari ke-4 tidak begitu lho ... tergantung (P5)"

" amis, terus biar wangi ... kalau sedang menstruasi lebih dijaga kebersihannya ... saya memberitahu pak guru ... biar nggak disuruh yang berat-berat (P5)"

"ibu nggak menjelaskan tentang membersihkan daerah kewanitaan (P1-7)"

"pakai handuk ... handuk sendiri (P1-3)"

"tidak disabun dan tidak dikeringkan (Pl-4)"

Remaja memiliki persepsi bahwa ada pantangan-pantangan tertentu yang harus dipatuhi saat mengalami menstruasi, antara lain tidak boleh keramas dan tidak boleh makan yang berminyak dan amis, mereka tidak tahu pasti alasan pantangan tersebut. Menurut beberapa partisipan, makanan yang amis akan menyebabkan darah menstruasi berbau amis. Hal ini diperkuat dengan pernyataan sebagai berikut:

"nggak boleh makan yang minyak gitu.. nggak tahu.. pernah dengar gitu.. (P1)"

"pindang nggak boleh.. katanya membuat darahnya itu amis.. saya sering disuruh menghindari, tapi mau terus.. hehe.. nggak makan (P5)"

"iya nggak boleh keramas.. kan di ngaji juga dijelaskan.. bukannya nggak boleh, tapi takut rambutnya itu rontok.. kalau menstruasi, kalau sisiran harus disimpan.. ya cuma diginiin.. ya kalau nanti di akhiratakhirat (P5; P6)"

Remaja mengelola limbah pembalut wanita yang sudah kotor dengan tidak benar. Mereka membuang pembalut ini di WC. Hal ini dibuktikan dengan pernyataan berikut:

"disobek itu.. dicuci dulu.. bisa mencuci di sekolahan. ada air.. dicuci, disobek kan bawahnya kayak ada kapas.. di wc nya kan $i$ **.. terus bawahnya kan plastik.. tapi kapasnya sudah tidak ada.. plastiknya dibuang di tempat sampah.. tidak dibungkus.. mencuci tidak menggunakan sabun.. di sana tidak ada sabun.. cuci tangan ke atas.. ke yang tempat untuk cuci piring.. terus pakai $s^{* * * * * * * . . ~ a d a ~ t e m p a t ~ c u c i ~}$ piring.. Cuma guru kalau makan siang (P5)"

"kalau saya di sekolahan bocor belum pernah.. ya itu di rumah.. ya dibuang ke WC semuanya. ya dicuci dulu.. (P6)"

\section{Remaja memerlukan sumber informasi yang bisa diakses dengan mudah dan privasi}

Sumber informasi yang didapatkan oleh remaja di pedesaan bervariasi, antara lain dari guru sekolah, guru mengaji, teman, membaca buku dan dari program acara televisi. Tidak ada diantara partisipan yang mengatakan mendapatkan informasi menstruasi dari ibunya. Pada dasarnya, remaja menginginkan ibu memberikan penjelasan kepada mereka tentang menstruasi ini dengan jelas dan benar. Hasil ini dibuktikan dengan pernyataan berikut: 
Eka Ratnawati

Kebutuhan Remaja Mempersiapkan Perawatan Kebersihan Menstruasi Di Daerah Pedesaan

"tanya tanya pada teman yang sudah mengalami begitu.. bagaimana rasanya menstruasi pertama kali? Dimana pertama kali menstruasi? Pertamanya di punggungnya, perutnya nggak sakit.. tapi terus mensnya di rumah malam hari ... di televisi itu ada acara berita Islami (P1)"

"dari buku pelajaran ... di mengaji iya, sama bu guru (P1, P5)’”

Remaja mengaku bahwa mereka lebih nyaman bertanya pada teman, karena lebih terbuka, walau sebenarnya kurang percaya atau ragu dengan penjelasan yang disampaikan oleh temannya. Hal ini dibuktikan dengan pernyataan berikut:

"lebih nyaman bertanya pada teman (P5)"

"karena lebih terbuka ... nggak percaya ... ragu ... dilakukan, tapi mencoba menanyakan lagi dengan yang lain (P6)”

\section{Perlu pemilihan waktu yang tepat dalam penyampaian informasi}

Memperbincangkan tentang menstruasi harus dilakukan dengan saat yang tepat dan suasana yang mendukung. Remaja mulai bertanya pada ibunya tentang menstruasi pada saat ngobrol santai di rumah, dan ibunya langsung memberikan penjelasan sebatas yang dipahaminya. Kebanyakan partisipan ibu menyampaikan belum memiliki pengetahuan yang lengkap dan benar tentang menstruasi, hanya 2 orang yang merasa cukup memiliki informasi yang benar, karena keduanya merupakan kader posyandu dan beberapa waktu telah mengikuti seminar kesehatan yang diadakan dinas kesehatan. Remaja bertanya pada ibunya kalau masih belum mengerti tentang menstruasi, walau sudah membaca dari buku. Hal ini dibuktikan dengan pernyataan berikut: "pas ngobrol santai terus tanya ... kalau menstruasi itu gimana? Terus dijelasin gini gini gini ... membaca buku itu kan terus nggak mudeng ... terus tanya ... (P5)"

Semua partisipan menginginkan penjelasan menstruasi diberikan kepada remaja sebelum mengalami menarche oleh ibu maupun ibu guru. Mereka mengharapkan hal ini agar lebih siap melakukan perawatan menstruasi dan tidak bingung serta takut atau panik apabila terjadi menarche. hal ini dibuktikan dengan pernyataan berikut:

"memilih penjelasan diberikan
sebelum menstruasi(P1-8)"
"karena kalau lagi M bisa tahu
bagaimana cara menjaga
kebersihan.. penjelasan dari
orangtua (P1)"
"ya sama.. tapi penjelasannya itu
kurang.. orangtua biar menjelaskan
makin jelas.. guru ngasih, orangtua
juga ngasih.. P6)"

\section{Remaja perlu bantuan awal saat mengalami menarche}

Beberapa partisipan yang telah mengalami menstruasi menceritakan keluhan fisik yang dialaminya, seperti sakit pinggang, sakit perut dan rasa tidak percaya diri jika darah membekas pada seragam yang dipakainya di sekolah. Ada 1 partisipan yang mengalami menarche di sekolah kemudian langsung pulang ke rumah karena ketakutan, dan beberapa hari tidak masuk sekolah karena keluhan fisik yang dirasakan. Ketika beberapa partisipan mengalami 
Eka Ratnawati

Kebutuhan Remaja Mempersiapkan Perawatan Kebersihan Menstruasi Di Daerah Pedesaan

menarche di rumah, maka mereka memberitahu ibunya, walau merasa ragu dan malu. Bagi partisipan yang memiliki saudara perempuan yang lebih tua, saat mengetahui bahwa telah mengalami menarche, maka kakak perempuannya memberikannya pembalut wanita untuk menampung darah menstruasi. Mereka ditanya apakah sudah bisa memakai pembalut, namun tidak diberitahu atau dicontohkan cara mengenakan pembalut tersebut. Remaja mendapat informasi cara memakai pembalut dari buku dan teman, namun belum pernah praktik langsung. Hal ini dibuktikan dengan pernyataan berikut:

"bilang sama orangtua ... ragu mau bilang apa nggak ... ya malu ... tidak percaya kalau sudah mens ... terus ibu bilang apa iya ... hehe ... langsung percaya (P5)",

"yang dikasih tahu pertama kali sih orangtua ... ya ibunya ... hehe ... ya langsung memberitahu gitu. Kakak saya kan udah punya pembalut, jadi saya pakai itu ... kakak saya yang ngasih ... sudah ... dari buku ... dari teman ... Cuma ngasih tahu ... dibayangkan begitu ... cara pemakaian pembalut (P6)",

\section{Tindakan responsif yang harus dilakukan saat terjadi menarche}

Menarche dapat terjadi kapan saja dan dimana saja, sehingga remaja bisa kaget dan panik apabila tidak dipersiapkan sejak awal tentang kondisi ini. Partisipan sudah memahami bahwa jika mengalami menarche di rumah, maka harus segera memberitahu ibu. Namun apabila menarche terjadi di sekolah, maka remaja harus memberitah ibu guru. namun ada 1 partisipan yang langsung pulang saat mengalami menarche di sekolah. Setelah ada orang dewasa yang tahu bahwa remaja telah mengalami menarche, maka akan bereaksi memberikan support dan bantuan agar remaja mengalami hal positif. Hasil ini dibuktikan dengan pernyataan berikut:

"bingung dan malu mau bilang sama orangtua.. ya malu (P1)"

"pulang ... saat tahu kalau mens (P3)"

\section{Remaja memerlukan fasilitas perawatan menstruasi yang layak}

Perawatan kebersihan menstruasi sangat berkaitan dengan adanya fasilitas yang menunjang, baik di rumah maupun di sekolah. Fasilitas ini salah satunya adalah toilet/kamar kecil, selain tempat khusus untuk membuang pembalut kotor. Semua partisipan mengatakan hal yang tidak nyaman mengenai kondisi toilet di sekolah, terutama saat sedang mengalami menstruasi. Kondisi toilet kotor, gelap, jadi satu dengan toilet laki-laki, tidak tersedia air bersih dan ada celah yang mereka khawatirkan tidak bisa menjaga privasi para siswi. Data ini dibuktikan dengan pernyataan:

"ada WC di sekolah jadi satu dengan laki-laki (P1-4). Pintu bisa dikunci ... air mati hampir setiap hari.. males ke kamar mandi.. kalau mau pipis ke kamar mandi uтum desa.. Deket (PI)"

"kadang kalau nggak ada air kotor. airnya mati (P1-2)"

"kadang-kadang bersih.. kadangkadang nggak.. sudah terpisah dengan yang laki-laki.. pintunya bisa ditutup dikunci.. ada celahnya (P6)" 
Eka Ratnawati

Kebutuhan Remaja Mempersiapkan Perawatan Kebersihan Menstruasi Di Daerah Pedesaan

\section{PEMBAHASAN}

Pentingnya informasi tentang menstruasi diberikan kepada remaja didukung oleh beberapa penelitian sebelumnya. Siklus menstruasi dipahami sebagai tanda vital yang memberikan informasi kesehatan secara keseluruhan pada remaja putri dan dewasa muda. Remaja putri sangat perlu untuk memantau siklus normal menstruasinya. Informasi yang benar tentang menstruasi normal perlu disampaikan pada remaja, orangtua, guru dan pihak yang terlibat. Remaja putri sering mengalami siklus menstruasi yang tidak teratur pada beberapa tahun pertama setelah menarche. Sejak awal, remaja sudah harus diberikan pemahaman untuk memantau dan mendokumentasikan siklus menstruasinya dengan sistem kalender. Usia rata-rata menarche adalah 12,8 tahun, yang didahului dengan perkembangan pubertas (perkembangan payudara) yang bisa dimulai sejak usia 8 tahun. Pada 1-2 tahun pertama setelah menarche siklus menstruasi tidak teratur. Menstruasi normal terjadi 2-7 hari dan pengeluaran darah setiap siklus $30 \mathrm{ml}$ (rentang 20-60 ml), terjadi sebelum usia 15 tahun, siklus menstruasi 21-45 hari (Hillard, 2014).

Penelitian lain menunjukkan bahwa kebanyakan remaja memahami bahwa menstruasi adalah fenomena normal dan merupakan indikasi kesehatan fisik dan mental. Sedikit yang merasa terganggu dan tidak nyaman, namun ada juga menunjukkan keduanya. Promosi kesehatan pada siswi di sekolah, terutama di daerah pedesaan direkomendasikan untuk dilakukan secara langsung dan lebih efektif meningkatkan pengetahuan remaja (Fakhri, Hamzehgardeshi, Azam, Golchin, \& Komili, 2012). Hal ini memberikan rekomendasi pada penelitian ini, agar orangtua dan guru sekolah bisa memberikan informasi dengan lebih jelas dan langsung kepada para remaja.

Komunikasi dan dukungan dari orangtua sangat penting dilakukan, dihubungkan dengan peningkatan perkembangan kesehatan dan perilaku kesehatan remaja yang diharapkan. Penelitian sebelumnya telah dilakukan dengan melibatkan remaja, ibu dan guru, mendapatkan hasil bahwa ibu adalah sumber informasi dan dukungan terbaik selama masa puber remaja, namun hanya sedikit yang melakukan komunikasi yang baik dalam pelaksanaannya. Remaja lebih menyukai kamunikasi yang dilakukan lebih awal dan diulang-ulang secara teratur. Ibu sering mengombinasikan topik tentang kematangan seksual dan menghindari pernikahan dini dalam pesan yang disampaikannya. Komunikasi ini didukung oleh kemampuan ibu, sikap hangat ibu dan hubungan ibu-anak. Tantangan yang dihadapi adalah tabu, rasa malu, isi pesan yang membingungkan, kurang pengetahuan ibu. Kemiskinan mempengaruhi ketersediaan dan motivasi ibu untuk melakukan komunikasi (Crichton, Ibisomi, \& Gyimah, 2012).

Hal ini sedikit berbeda dengan penelitian yang dilakukan di Desa 
Eka Ratnawati

Kebutuhan Remaja Mempersiapkan Perawatan Kebersihan Menstruasi Di Daerah Pedesaan

Simpar, dimana tidak ada satupun partisipan yang mendapatkan informasi dari ibunya, walau mereka sangat menginginkan hal tersebut. Ibu sendiri sebenarnya paham bahwa harus menyampaikan informasi ini. Hal ini terjadi karena adanya tabu, rasa malu, serta ibu mengalami kurang informasi yang jelas dan benar tentang menstruasi.

Hasil dari penelitian lain yang berbeda dengan penelitian ini adalah sebagian besar remaja paham tindakan yang harus dilakukan saat menarche, namun hanya $39 \%$ yang menyatakan bahwa mereka telah dipersiapkan sebelumnya. Terkait dengan sikap menstruasi, remaja banyak menyampaikan perasaan negatif dan penolakan daripada perasaan positif. Remaja yang sebelumnya pernah berdiskusi dengan ibunya tentang aspek emosi menstruasi lebih memiliki perasaan positif. Mendiskusikan aspek emosional menarche sangat perlu untuk mempersiapkan diri mengalami menarche, dan memiliki sikap positif saat menstruasi. Informasi pengetahuan biologis dan praktik tindakan perawatan menstruasi diperlukan untuk diberikan dengan pendekatan emosional (Marván \& Molina-Abolnik, 2012). Pendekatan emosional ini yang kurang didapatkan pada partisipan penelitian ini, ibu menganggap bahwa akan sangat wajar anak remajanya akan tahu dengan sendirinya tentang menstruasi dari teman atau televisi.

Remaja perlu dipersiapkan sejak dini untuk mendapatkan pengalaman positif menarche dan menstruasi. Hal ini sesuai dengan hasil penelitian lain yang menyatakan bahwa gejala fisiologis, pengetahuan tentang menstruasi, persiapan menarche, pemberi informasi awal, kualitas informasi yang diberikan dan reaksi emosional saat mengalami menarche memegang peran penting selama menarche dan menstruasi. Remaja yang sudah dipersiapkan lebih dini memiliki pengalaman yang positif dibandingkan yang tidak dipersiapkan. Pengalaman positif ini meliputi pemahaman atas terjadinya peristiwa alami, tertarik dan senang karena merasa sudah tumbuh dewasa (Liu, Chen, \& Peng, 2012).

Bantuan yang harus diberikan pada remaja selama menarche dan menstruasi adalah dengan penguatan tindakan perawatan kebersihan menstruasi yang harus bisa dilakukan sendiri oleh remaja. Perawatan kebersihan menstruasi merupakan tantangan yang signifikan untuk remaja dan wanita di negara miskin dan berkembang. Efek perawatan kebersihan menstruasi yang buruk memang belum jelas, namun sangat mungkin diduga menyebabkan infeksi saluran reproduksi (Sumpter \& Torondel, 2013).

Hal awal yang harus dipersiapkan untuk remaja sebelum mengalami menarche adalah memesannya untuk memberitahu orang terdekat (ibu atau ibu guru) saat terjadi menarche (baik di rumah maupun di sekolah). Dari penelitian lain, menyatakan bahwa remaja yang memberitahu ibunya atau gurunya saat mengalami menarche menyatakan 
Eka Ratnawati

Kebutuhan Remaja Mempersiapkan Perawatan Kebersihan Menstruasi Di Daerah Pedesaan

bahwa mengalami penurunan rasa takut, karena dapat menyampaikan perasaannya pada ibu/guru, sedangkan sebagian menyembunyikan fakta ini dari siapapun (Marvan, Vacio, Yanez, \& Hernandes, 2007). Hal ini sama dengan hasil penelitian yang dilakukan bahwa ibu yang pertama diberitahu saat terjadi menarche di rumah, walau ada rasa takut dan malu. Namun ada 1 partisipan yang mengalami menarche di sekolah, memutuskan langsung pulang ke rumah dan dalam beberapa hari ke depan tidak masuk sekolah karena masalah ini.

Ibu memiliki peran penting dalam memberikan bantuan awal saat anak remajanya menyampaikan bahwa telah mengalami menarche. Ibu segera memberikan informasi apa yang harus dilakukan saat anaknya menarche (cara membersihkan daerah kewanitaan saat menstruasi), dan ibu mengekspresikan bahagia, mengucapkan selamat, memberikan ciuman, memeluk, memberikan hadiah karena anaknya telah tumbuh dengan normal. Semua bantuan awal ini memberikan kesan positif pada remaja (Ozdemir, Nazik, \& Pasinlioglu, 2010). Hasil penelitian ini tidak sama dengan penelitian yang dilakukan, ibu memang memberikan pembalut, namun tidak mengajarkan cara memakainya, dan tidak mengajarkan cara membersihkan daerah kewanitaan dengan benar. Remaja akhirnya melakukan perawatan kebersihan menstruasi sesuai dengan persepsi dan pengetahuan masing-masing yang belum tentu dipertanggung jawabkan kebenarannya.
Respons remaja saat mengalami menarche atau menstruasi adalah rasa khawatir atau malu, bahkan takut apabila cairan darah tumpah mengenai rok atau baju yang dikenakan. Banyak siswi hanya memiliki seragam sekolah yang terbatas (bahkan dengan warna bahan yang terang) dan memiliki celana dalam dengan jumlah terbatas untuk bersalin di sekolah, hal ini yang mengakibatkan mereka merasa cemas karena harus segera mencuci noda darah yang ada untuk dapat mengenakan seragamnya kembali. Dan proses berganti pembalut, pakaian dan mencuci noda darah ini memerlukan waktu ijin yang banyak, saat pelajaran sedang berlangsung (Jewitt \& Ryley, 2014). Hal ini sama dengan hasil penelitian yang dilakukan, bahwa remaja takut kalau "tembus/bocor" di rok seragam yang dikenakan. Ini menjadi alasan para siswi takut kalau disuruh maju ke depan kelas oleh guru saat sedang menstruasi.

Perawatan menstruasi sangat penting untuk dilakukan, namun banyak remaja yang belum mengetahui hal ini. Hasil penelitian lain menyimpulkan bahwa tindakan yang tidak bersih dan kurangnya pemahaman pada remaja memerlukan tindakan dari petugas kesehatan. Beberapa praktik yang tidak sehat saat menstruasi adalah tidak diperbolehkan mandi, menggunakan bahan yang tidak bersih untuk menyerap darah menstruasi (menggunakan kain-kain sisa) yang dicuci namun tidak dijemur di bawah sinar matahari. Respons psikologis yang muncul adalah 
Eka Ratnawati

Kebutuhan Remaja Mempersiapkan Perawatan Kebersihan Menstruasi Di Daerah Pedesaan

ketakutan saat mengalami menarche (Ali \& Rizvi, 2010). Sikap positif terhadap menstruasi dan pengalaman menstruasi adalah hal yang penting terhadap harga diri wanita dan kepuasan terhadap fungsi tubuhnya (Hoerster, Chrisler, \& Rose, 2008).

Kemampuan remaja melakukan perawatan kebersihan menstruasi dipengaruhi beberapa faktor, seperti status pendidikan ibu, pengetahuan remaja, dan kecukupan ekonomi. Kesadaran akan kebutuhan pengetahuan menstruasi dan perawatannya sangat penting. Pendidikan kesehatan sebaiknya direncanakan untuk menciptakan kesadaran akan perawatan menstruasi yang baik (Kumar \& Srivastava, 2011; Upashe, Tekelab, \& Mekonnen, 2015). Menarche dan menstruasi berhubungan dengan rasa malu dan hambatan emosional lain dalam mengelola menstruasinya dan menyembunyikan status menstruasi. Pada sekolah negeri, kurangnya privasi toilet yang disediakan menyebabkan remaja merasa malu saat sedang mengalami menstruasi. Sulitnya melakukan kebersihan terjadi karena terbatasnya ketersediaan air mengalir atau tampungan air, jarak dengan toilet yang jauh, tidak adanya sabun dan tidak ada fasilitas untuk membuang pembalut yang kotor (Jewitt \& Ryley, 2014). Data ini menguatkan hasil penelitian yang telah dilakukan, bahwa fasilitas untuk perawatan kebersihan menstruasi harus diberikan dengan layak dan terhormat bagi para remaja putri.
Penelitian lain menguatkan data hasil penelitian ini, yakni banyak remaja yang merasa terhambat dalam melakukan perawatan menstruasi, karena fasilitas toilet sekolah yang kurang memadai, terutama ketersediaan air bersih (Sommer, 2010). Hambatan tindakan perawatan menstruasi yang dihadapi oleh remaja adalah karena ketersediaan air yang tidak adekuat, fasilitas sanitasi dan pembuangan limbah menstruasi yang tidak memenuhi privasi dan martabat, dan tidak adanya panduan untuk membantu remaja agar percaya diri selama mengalami menstruasi di sekolah (Sommer, Ackatia-Armah, Connolly, \& Smiles, 2015).

Di tempat lain, kebanyakan remaja menggunakan pembalut wanita untuk menyerap darah menstruasi, sama dengan kebiasaan masyarakat di setting penelitian ini. Walaupun sebenarnya mereka paham bahwa pembalut yang dipergunakan ini tidak ramah lingkungan, tidak larut air dan bisa menyumbat saluran air. Hanya beberapa yang menggunakan pembalut yang bisa dipakai ulang. Banyak wanita yang mengekspresikan bahwa kurangnya privasi pada fasilitas sanitasi yang tersedia, kurangnya pilihan tempat pembuangan pembalut kotor dan akses air bersih, dan banyak toilet di luar ruangan yang tidak memberikan privasi pada pemakainya (Scorgie et al., 2016).

\section{KESIMPULAN}

Remaja putri usia 10-14 tahun harus dipersiapkan sedini mungkin (lebih baik sejak usia 8 tahun) saat 
Eka Ratnawati

Kebutuhan Remaja Mempersiapkan Perawatan Kebersihan Menstruasi Di Daerah Pedesaan

mulai muncul gejala pre menarche agar memiliki pengalaman positif menarche atau menstruasi. Pengalaman positif ini akan menjadikan remaja putri mampu melakukan perawatan kebersihan menstruasi dengan benar dan memiliki kesiapan mental saat terjadi menarche dimanapun dan kapanpun. Sekolah dan rumah tangga memiliki kewajiban untuk menyediakan fasilitas sanitasi toilet dengan air bersih dan mengalir, sabun cuci tangan, tissue dan tempat khusus untuk pembuangan pembalut kotor. Selain itu, sekolah perlu memiliki panduan perawatan kebersihan menstruasi yang mudah dimengerti oleh para siswi dan disosialisasikan dengan baik. Ibu dan guru memiliki peran besar dalam menyampaikan seluruh informasi perawatan kebersihan menstruasi kepada remaja.

\section{DAFTAR PUSTAKA}

Ali, T. S., \& Rizvi, S. N. (2010). Menstrual knowledge and practices of female adolescents in urban Karachi, Pakistan. Journal of Adolescence. https://doi.org/10.1016/j.adolesce nce.2009.05.013

Badan Pusat Statistik, Nasional, B. K. dan K. B., Kesehatan, K., \& DHS, M. (2013). Survei Demografi dan Kesehatan Indonesia 2012 Kesehatan Reproduksi Remaja. JAKARTA: Badan Pusat Statistik Nasional, Badan Kependudukan dan Keluarga Berencana Kesehatan, Kementerian DHS, MEASURE.

Crichton, J., Ibisomi, L., \& Gyimah, S. O. (2012). Mother-daughter communication about sexual maturation, abstinence and unintended pregnancy: Experiences from an informal settlement in Nairobi, Kenya. Journal of Adolescence. https://doi.org/10.1016/j.adolesce nce.2011.06.008

Fakhri, M., Hamzehgardeshi, Z., Azam, N., Golchin, H., \& Komili, A. (2012). Promoting menstrual health among persian adolescent girls from low socioeconomic backgrounds: a quasi-experimental study. $B M C$ Public Health, 12, 193. https://doi.org/10.1186/14712458-12-193

Hillard, P. J. A. (2014). Menstruation in Adolescents: What Do We Know and What Do We Do with the Information. Journal of Pediatric and Adolescent Gynecology. https://doi.org/10.1016/j.jpag.201 3.12 .001

Hoerster, K., Chrisler, J. C., \& Rose, J. G. (2008). Attitudes Toward and Experience with Menstruation in the US and India. Women \& Health, 38(3), 77-95. https://doi.org/10.1300/J013v38n 03_06

Jewitt, S., \& Ryley, H. (2014). It's a Girl Thing: Menstruation, School Attendance, Spatial Mobility and Wider Gender Inequalities in Kenya. Geoforum, 56, 137-147. https://doi.org/http://dx.doi.org/1 0.1016/j.geoforum.2014.07.006

Kumalasari, I., \& Andhyantoro, I. (2013). Kesehatan Reproduksi untuk Mahasiswa Kebidanan dan Keperawatan. Jakarta: Salemba Medika.

Kumar, A., \& Srivastava, K. (2011). Cultural \& Social Practices Regarding Menstruation among Adolescent. Social Work in Public Health. 
Eka Ratnawati

Kebutuhan Remaja Mempersiapkan Perawatan Kebersihan Menstruasi Di Daerah Pedesaan

https://doi.org/10.1080/19371918 .2010 .525144

Kusmiran, E. (2013). Kesehatan Reproduksi Remaja dan Wanita. Jakarta: Salemba Medika.

Liu, H. L., Chen, K. H., \& Peng, N. H. (2012). Cultural Practices Relating to Menarche and Menstruation among Adolescent Girls in Taiwan-Qualitative Investigation. Journal of Pediatric and Adolescent Gynecology.

https://doi.org/10.1016/j.jpag.201 1.08 .006

Marván, M. L., \& Molina-Abolnik, M. (2012). Mexican Adolescents' Experience of Menarche and Attitudes Toward Menstruation: Role of Communication Between Mothers and Daughters. Journal of Pediatric and Adolescent Gynecology.

https://doi.org/10.1016/j.jpag.201 2.05.003

Marvan, M. L., Vacio, A., Yanez, G. G., \& Hernandes, G. E. (2007). Attitudes Toward Menarche Among Mexican Preadolescents. Women \& Health, 46(1). https://doi.org/10.1300/J013v46n 01_02

Ozdemir, F., Nazik, E., \& Pasinlioglu, T. (2010). Determination of the Motherly Reactions to Adolescents' Experience of Menarche. Pediatric Adolescent Gynecology.

https://doi.org/10.1016/j.jpag.200 9.09.001

Ratnawati, E., Prabandari, Y. S., \& Nisman, A. (2018). Experiences of Mother and Daughter Communication Responding to Menarche in Rural Area: A Qualitative Study. In Suhartini, R. Ka. Sari, N. R. Yulianti, A. Nuraeni, H. Kusuma, F. T. Kusumawati, ... A. D. Larasati
(Eds.), Abstract Book Central Java International Nursing Conference (1st ed., p. 30). Semarang: PPNI Jateng. Retrieved from file:///D:/ic/cjincabstract-book.pdf\%0D

Scorgie, F., Foster, J., Stadler, J., Phiri, T., Hoppenjans, L., Rees, H., \& Muller, N. (2016). "Bitten By Shyness": Menstrual Hygiene Management, Sanitation, and the Quest for Privacy in South Africa. Medical Anthropology, $35(2)$.

https://doi.org/10.1080/01459740 .2015 .1094067

Sommer, M. (2010). Where the Education System and Women's Bodies Collide: The Social and Health Impact of Girls' Expereiences of Menstruation and Schooling in Tanzania. Journal of Adolescence, 33, 521529.

https://doi.org/10.1016/j.adolesce nce.2009.03.008

Sommer, M., Ackatia-Armah, N., Connolly, S., \& Smiles, D. (2015). A comparison of the menstruation and education experiences of girls in Tanzania, Ghana, Cambodia and Ethiopia. Compare.

https://doi.org/10.1080/03057925 .2013 .871399

Sugiyono. (2015). Memahami Penelitian Kualitatif. Bandung: $\mathrm{CV}$ alfabeta.

Sumpter, C., \& Torondel, B. (2013). A Systematic Review of the Health and Social Effects of Menstrual Hygiene Management. PLoS ONE, $\quad$ 8(4). https://doi.org/10.1371/journal.po ne.0062004

Tong, A., Sainsbury, P., \& Craig, J. (2007). Consolidated criteria for reporting qualitative research (COREQ) : a 32-item checklist 
Eka Ratnawati

Kebutuhan Remaja Mempersiapkan Perawatan Kebersihan Menstruasi Di Daerah Pedesaan

for interviews and focus groups. International Journal for Quality in Health Care, 19, 349-357. https://doi.org/10.1093/intqhc/mz $\mathrm{m} 042$

Upashe, S. P., Tekelab, T., \& Mekonnen, J. (2015). Assessment of knowledge and practice of menstrual hygiene among high school girls in Western Ethiopia. BMC Women's Health, 15(1).https://doi.org/10.1186/s12 905-015-0245-7 